\title{
Integrating Multiple Inputs Into an Artificial Pancreas System: Narrative Literature Review
}

Chirath Hettiarachchi ${ }^{1}$, BSc, MSc; Elena Daskalaki ${ }^{1}, \mathrm{PhD}$; Jane Desborough ${ }^{2}$, RN, RM, MPH, PhD; Christopher J Nolan $^{3,4}$, BMedSci, MBBS, PhD; David O’Neal ${ }^{5,6}$, MBBS, MD; Hanna Suominen ${ }^{1,7,8}$, MSc, MEdL, PhD, Docent

${ }^{1}$ School of Computing, College of Engineering and Computer Science, The Australian National University, Canberra, Australia

${ }^{2}$ Department of Health Services Research and Policy, Research School of Population Health, College of Health and Medicine, The Australian National University, Canberra, Australia

${ }^{3}$ Australian National University Medical School, College of Health and Medicine, The Australian National University, Canberra, Australia

${ }^{4}$ John Curtin School of Medical Research, College of Health and Medicine, The Australian National University, Canberra, Australia

${ }^{5}$ Department of Medicine, University of Melbourne, Melbourne, Australia

${ }^{6}$ Department of Endocrinology and Diabetes, St Vincent's Hospital Melbourne, Melbourne, Australia

${ }^{7}$ Data61, Commonwealth Industrial and Scientific Research Organisation, Canberra, Australia

${ }^{8}$ Department of Computing, University of Turku, Turku, Finland

\section{Corresponding Author:}

Chirath Hettiarachchi, BSc, MSc

School of Computing

College of Engineering and Computer Science

The Australian National University

Hanna Neumann Building

145 Science Road, Acton

Canberra, 2600

Australia

Phone: 61414066695

Email: chirath.hettiarachchi@anu.edu.au

\section{Abstract}

Background: Type 1 diabetes (T1D) is a chronic autoimmune disease in which a deficiency in insulin production impairs the glucose homeostasis of the body. Continuous subcutaneous infusion of insulin is a commonly used treatment method. Artificial pancreas systems (APS) use continuous glucose level monitoring and continuous subcutaneous infusion of insulin in a closed-loop mode incorporating a controller (or control algorithm). However, the operation of APS is challenging because of complexities arising during meals, exercise, stress, sleep, illnesses, glucose sensing and insulin action delays, and the cognitive burden. To overcome these challenges, options to augment APS through integration of additional inputs, creating multi-input APS (MAPS), are being investigated.

Objective: The aim of this survey is to identify and analyze input data, control architectures, and validation methods of MAPS to better understand the complexities and current state of such systems. This is expected to be valuable in developing improved systems to enhance the quality of life of people with T1D.

Methods: A literature survey was conducted using the Scopus, PubMed, and IEEE Xplore databases for the period January 1, 2005, to February 10, 2020. On the basis of the search criteria, 1092 articles were initially shortlisted, of which 11 (1.01\%) were selected for an in-depth narrative analysis. In addition, 6 clinical studies associated with the selected studies were also analyzed.

Results: Signals such as heart rate, accelerometer readings, energy expenditure, and galvanic skin response captured by wearable devices were the most frequently used additional inputs. The use of invasive (blood or other body fluid analytes) inputs such as lactate and adrenaline were also simulated. These inputs were incorporated to switch the mode of the controller through activity detection, directly incorporated for decision-making and for the development of intermediate modules for the controller. The validation of the MAPS was carried out through the use of simulators based on different physiological models and clinical trials.

Conclusions: The integration of additional physiological signals with continuous glucose level monitoring has the potential to optimize glucose control in people with T1D through addressing the identified limitations of APS. Most of the identified additional inputs are related to wearable devices. The rapid growth in wearable technologies can be seen as a key motivator regarding MAPS. 
However, it is important to further evaluate the practical complexities and psychosocial aspects associated with such systems in real life.

(JMIR Diabetes 2022;7(1):e28861) doi: 10.2196/28861

\section{KEYWORDS}

diabetes mellitus, type 1; pancreas, artificial; algorithms; multivariate analysis; insulin infusion systems; control systems

\section{Introduction}

\section{Background}

In health, pancreatic islet $\beta$-cells respond to metabolic and neurohormonal signals to secrete insulin into the portal vein at finely controlled variable rates to ensure that blood glucose level and overall metabolic homeostasis are maintained. Diabetes is a metabolic disease characterized by elevated blood glucose concentrations as a consequence of an absolute deficiency of insulin secretion or inadequate insulin secretion to compensate for ineffective insulin action. Type 1 diabetes (T1D) is caused by the autoimmune destruction of the islet $\beta$-cells and results in absolute insulin deficiency [1]. An inability to match insulin delivery with an individual's changing insulin requirements results in either hypoglycemia (low blood glucose level) or hyperglycemia (high blood glucose level). Hypoglycemia, if severe, may result in loss of consciousness, seizures, or even death. Long-term exposure to hyperglycemia results in complications such as blindness, limb amputations, and cardiovascular disease. Maintaining blood glucose levels in a healthy range is essential for the avoidance of severe shortand long-term complications of diabetes [1].

The discovery and use of exogenous insulin administration since 1921 as a therapeutic agent has been life saving for people living with T1D. More recently, pancreas and islet cell transplants have also provided a solution for T1D, although organ donation shortage, the risks of surgery, and the need for immunosuppression are limiting factors [2]. As a result, there is a continued reliance on the subcutaneous administration of exogenous insulin to treat this condition. There have been continuous advancements in insulin preparations [3], insulin delivery [4], and blood glucose level monitoring [5]. Until recent years, best practice treatment of T1D, as was established in the Diabetes Control and Complications Trial [6], involved frequent self-monitoring of blood glucose level through using finger pricks to access capillary blood and multiple daily injections of short- and long-acting insulins. Information from the self-monitoring of blood glucose level as well as the carbohydrate content of meals and planned exercise informed the titration of insulin doses. The advent of rapid-acting insulin analogs, continuous glucose monitoring (CGM), continuous subcutaneous infusion of insulin (CSII), shortcomings in manual insulin-dose determination, and the significant psychological burden [7] have motivated the development of the artificial pancreas (AP; or AP systems [APS]) [8].

Although the concept of the AP has been around for $>40$ years, with the Biostator [9] identified as the first closed-loop glucose controlling system or AP [10], it is only in the last few years that the use of the AP has become a clinical reality. The first Food and Drug Administration (FDA)-approved commercial AP was released in 2016 in the United States, with a second system more recently approved [11,12]. The basic components of the APS are a sensor measuring subcutaneous interstitial fluid glucose on a near-continuous basis, a pump infusing rapid-acting insulin into the subcutaneous tissue, and a control algorithm (also known as the controller) that uses glucose measurements as the main input to calculate and operate the required rate of insulin infusion as the output (Figure 1). Proportional integral derivative control, model predictive control (MPC), fuzzy logic [13-15], adaptive control [16,17], and reinforcement learning [18] have been used in the recent past for controller development. The FDA has categorized the AP as a class III medical device, which is considered high risk. Hence, an investigation device exemption is required before conducting a clinical trial [19]. This requires initial testing of the proof of concept through animal trials, which is a time-consuming and costly exercise. A critical step toward AP advancement was the development of physiological models and simulators, which enabled the tuning and testing of different control algorithms in silico before conducting clinical studies, ensuring safety. The minimal model of glucose kinetics [20], the Sorenson model [21], the Hovorka model [22], the UVA/PADOVA simulator [23], the mGIPsim simulator [24], and the in silico patient population by Resalat et al [25] are some of the widely used models. The UVA/PADOVA simulator is currently the only FDA-approved simulator. 
Figure 1. The basic system architecture of the artificial pancreas.

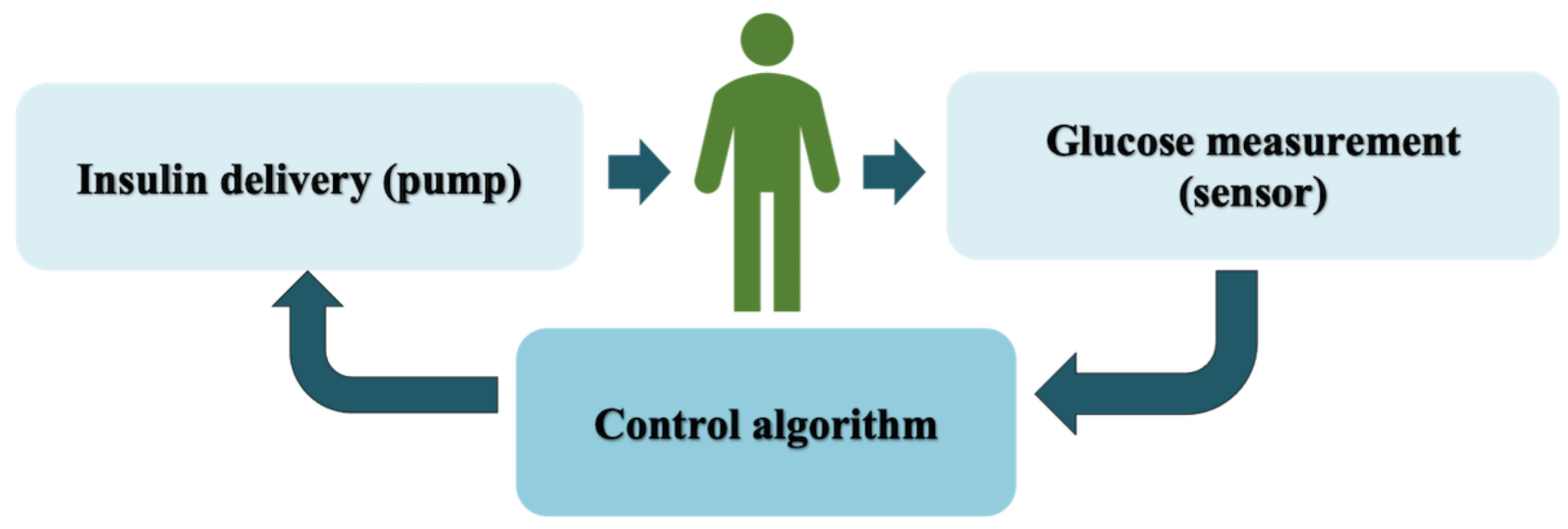

The major challenges with respect to the APS control algorithms relate to (1) delays in the onset and offset of insulin action because of delays of its absorption from subcutaneous depots (from CSII delivery) into the blood and (2) a time lag between glucose levels measured in subcutaneous interstitial fluid and blood glucose levels measured by currently available CGM devices. These limitations of APS imposed by the pharmacokinetics of subcutaneously delivered insulin and measured glucose levels are most evident in situations in which blood glucose levels and insulin requirements change rapidly and unexpectedly. These include meals, exercise, stressful events, and in response to acute illnesses. The current APS are hybrid closed-loop systems that require user input regarding meals and exercise; hence, similar to previous treatment methods, there remains a cognitive burden, affecting the quality of life of people with T1D [26]. Despite these limitations, systematic reviews and meta-analyses have verified that APS have shown better performance than conventional pump therapy [27]. However, there is still significant room for improvement.

Approaches used for improving APS functionality include advances in CGM accuracy and reliability; the development of faster-acting insulin analogs; and dual hormone infusion systems [28] in which glucagon, which can prevent hypoglycemia, as well as insulin can be delivered independently through the use of a controller. Complications of T1D can be related to meals, exercise, stress, and illness, all of which may affect glucose homeostasis. Current systems are unable to recognize these events and rely almost entirely upon inputs based on glucose level measurements and a record of the amount of insulin delivered. Inputs in addition to glucose level measurements may overcome some of the limitations of the current-generation APS. There has been recent focus on integrating additional external inputs captured from wearable devices and invasive sensors as part of experimental multi-input APS (MAPS). The addition of various signal inputs (eg, lactate and heart rate [HR]) is expected to provide more information and support the automatic identification of activities such as meals, exercise, sleep, stress, and other biological variations that affect the glucose profile [29]. The early detection of these activities would also help to counter limitations arising from CGM sensor delays [30]. This is also expected to reduce cognitive burden through lessening user interaction, leading to a better quality of life [31]. The rapid development of wearable sensor technologies can be identified as a strong motivator with respect to MAPS; however, it is important to analyze the potential improvement and additional device burden arising through the use of these systems.

\section{Objectives}

The main objective of this survey is to identify and review the MAPS that have been proposed to date in terms of used inputs, control architectures, and validation methods. To develop better systems, it is critical to understand the current state of MAPS and identify associated complexities. We aim to achieve this through conducting an in-depth analysis of previous related studies. The current pace of APS development has been slow, prompting movements such as \#WeAreNotWaiting by people with T1D, which focuses on do-it-yourself APS [32]. This synthesis may accelerate work on developing improved MAPS. This survey identified a variety of additional signals that have been integrated into experimental APS. Most of the reviewed publications focused upon noninvasive inputs from wearable devices. These additional input signals have been integrated into different architectures to augment the controllers, in particular (1) for activity detection and switching of controller modes, (2) as direct inputs to the controller for decision-making, and (3) for the development of intermediate modules of the controller (eg, hypoglycemia prediction or meal detection). A variety of physiological models, simulation environments, and clinical studies have been used for validation of the results. A detailed analysis is presented in later sections.

\section{Methods}

\section{Overview}

The survey was conducted by 3 independent reviewers $(\mathrm{CH}$, $\mathrm{ED}$, and HS) with research backgrounds in engineering, signal processing, machine learning, and health informatics, supported by a research librarian. The first reviewer conducted a systematic literature search and shortlisted studies through title and abstract screening. The second and third reviewers provided input to select the final studies for the survey and conducted the analysis. Throughout the reviewing process the researchers obtained valuable clinical expertise from 2 endocrinologists actively involved in T1D management and lived experience insights from young people with T1D within the Health Experience Team of the Our Health in Our Hands [33] strategic initiative of the Australian National University. 
The literature survey was conducted according to the PRISMA (Preferred Reporting Items for Systematic Reviews and Meta-Analyses) framework [34]. We searched Scopus and IEEE Xplore (to capture engineering studies on APS development, including multiple-input scenarios) and PubMed (to capture APS clinical studies conducted corresponding to the identified engineering approaches) databases between January 1, 2005, and February 10, 2020. The survey focused on analyzing and summarizing the different input sources, in addition to glucose level measurements, integrated into MAPS; control algorithms; architectures; and the validation methodologies used. The clinical transition of the identified studies was also considered to obtain a complete picture of the current state of progress of MAPS developments. The study selection process was carried out in 4 steps (Figure 2).

Figure 2. Study selection and identification flowchart. MAPS: multi-input artificial pancreas systems.

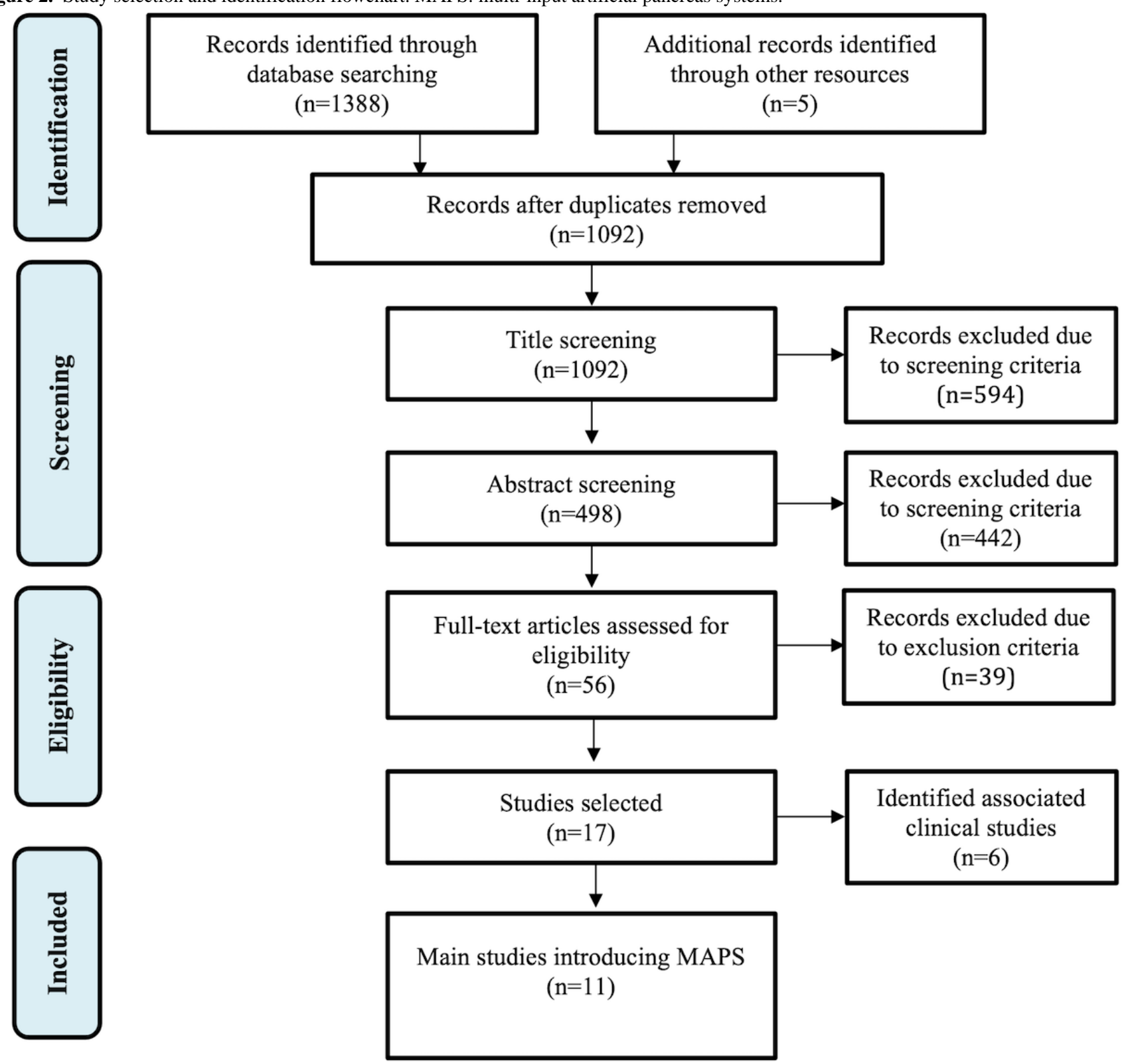

\section{Identification Phase}

A broad search query (Table 1) was developed to identify all papers related to control of the APS. The search query was not restricted further to ensure that all studies related to MAPS were captured. For the Scopus database, the search was restricted to articles and conference proceedings related to the subject areas of engineering, computer science, mathematics, decision sciences, and multidisciplinary specializations. The subject area restriction was not possible in PubMed; thus, the query was adjusted to exclude review articles and only include research related to humans. No additional filtering was carried out in the IEEE Xplore database because of it specific focus on computer science and electrical engineering. Additional records were identified through following the references in the selected studies (Multimedia Appendix 1). 
Table 1. Search queries resulting in the identified studies $(\mathrm{N}=1388)$.

\begin{tabular}{|c|c|c|}
\hline Database & Search strategy & Studies, n (\%) \\
\hline Scopus & $\begin{array}{l}(((\text { close } * \text { AND loop }) \text { AND }(\text { diabet* OR } t 1 d)) \text { OR artificial W/2pancreas) AND (control*); (filter: subject area } \\
\text { and article type) }\end{array}$ & $668(48.12)$ \\
\hline PubMed & $\begin{array}{l}\left.\left(\left(\left(\text { close }^{*} \mathrm{AND} \text { loop }\right) \text { AND }(\text { diabet } * \text { OR } \text { tld })\right) \text { OR artificial W/2pancreas }\right) \text { AND (control }{ }^{*}\right) \text { NOT (review*); (filter: } \\
\text { humans) }\end{array}$ & $393(28.31)$ \\
\hline IEEE Xplore & $\left(\left(\left(\right.\right.\right.$ close $^{*} \mathrm{AND}$ loop $)$ AND (diabet $*$ OR $\left.\left.t 1 d\right)\right)$ OR artificial pancreas $)$ AND control* & $327(23.56)$ \\
\hline
\end{tabular}

\section{Screening Phase}

Papers identified from the database search and other resources were first analyzed to remove duplicates. The titles and abstracts of the remaining papers were screened, where papers focusing on animal studies; CGM sensor development and errors analysis; insulin pumps; other aspects of the APS (eg, safety, user experience, and psychosocial aspects); physiological modeling; studies related to the chemical, biological, and medical aspects of APS design; studies focusing on developing submodules for the AP (eg, glucose-level estimation and meal detection); studies without additional input signals; and other irrelevant studies were excluded.

\section{Eligibility Phase}

The remaining full papers were analyzed and included in the study if the following selection criteria were met: (1) a control algorithm or architecture is present, (2) external additional inputs are used for the controller design (ie, in addition to CGM measurements, and the additional inputs are not control inputs, such as the coinfusion of glucagon), and (3) a validation is conducted in silico or in vivo (in humans). These criteria were formulated to encompass the 3 main verticals of the survey to understand and summarize the use of additional wearables in AP design, AP development technologies, and validation methodologies.

\section{Inclusion Phase}

Finally, the selected studies $(\mathrm{N}=17)$ were categorized into two groups: studies that introduce different unique MAPS (11/17, $65 \%)$ and their associated clinical studies $(6 / 17,35 \%)$. It is important to note that some of the studies in the first category also included clinical trial results $(3 / 11,27 \%)$. This separation was required to avoid the duplication of similar APS and ensure the overall analysis of the identified technical criteria of the unique MAPS studies. The main studies were analyzed based on the additional inputs used, APS controller design, and validation methodologies. The clinical studies were analyzed to discuss the feasibility of MAPS.

\section{Quality Assessment}

A quality assessment of the selected 17 studies were carried out using the Critical Appraisal Skills Programme Tool [35] (Multimedia Appendix 2 [36-52]). It is important to note that the main issues highlighted by the assessment were (1) difficulty in ascertaining the risk of bias in data collection or simulation data and (2) the failure of the study reports to provide sufficient information regarding ethical approvals.

\section{Results}

\section{Results Overview}

The analysis first identified the research groups working in the area of MAPS based on the selected studies and their clinical trials. Next, the shortlisted studies were evaluated based on the following main dimensions: (1) the types of additional signals used and their impact on glucose regulation, (2) the control algorithms and architectures, and (3) the validation methodologies.

\section{Research Groups Focusing on MAPS}

The Illinois Institute of Technology and Oregon Health \& Science University were identified as the 2 main research groups developing MAPS, having produced $45 \%(5 / 11)$ of the main studies and $83 \%(5 / 6)$ of the associated clinical studies (Table 2 ). The diversity of researchers from different domains authoring the selected studies highlights the importance of multidisciplinary teams in APS development. 
Table 2. Breakdown of main research groups focusing on developing multi-input artificial pancreas systems $(\mathrm{N}=17)^{\mathrm{a}}$.

\begin{tabular}{ll}
\hline Research group & $\begin{array}{l}\text { Selected main studies } \\
(\mathrm{n}=11), \mathrm{n}(\%)\end{array}$ \\
\hline $\begin{array}{l}\text { - Illinois Institute of Technology, United States } \\
\text { - } \quad \text { Department of Chemical and Biological Engineering } \\
(\mathrm{n}=6), \mathrm{n}(\%)\end{array}$ & 3 [36-38] \\
- Department of Biomedical Engineering \\
- Department of Biobehavioral Health Science \\
- Department of Pediatrics \\
- University of Illinois Chicago, United States \\
- College of Nursing \\
University of Chicago, United States \\
- Biological Sciences Division
\end{tabular}

- $\quad$ Michigan State University, United States

- Sparrow Medical Group

- $\quad$ Oregon Health \& Science University, United States

- Department of Biomedical Engineering

- Department of Medicine

- Division of Endocrinology, Harold Schnitzer Diabetes Health Center

- Oregon Clinical and Translational Research Institute Biostatistics \& Design Program

- Department of Medicine, Division of Health Promotion and Sports Medicine

- Instituto Potosino de Investigación Científica y Tecnológica, Mexico

- Division de Matematicas Alicadas

- Biodinamica y Sistemas Alineales

- National University of Sciences \& Technology, Pakistan

- Department of Electrical Engineering

- Northwestern Polytechnical University, China

- School of Automation

- Center for Emerging Sciences Engineering and Technology, Pakistan

- Department of Electronics Engineering

- $\quad$ Stanford University, United States

- Division of Pediatric Endocrinology

- Rensselaer Polytechnic Institute, United States

- Department of Chemical and Biological Engineering

- University of Virginia, Charlottesville, Virginia, United States

- Center for Diabetes Technology, Division of Pediatric Endocrinology, Department of Pediatrics

- Division of Endocrinology, Department of Medicine

- Virginia Commonwealth University

- Division of Pediatric Endocrinology, Department of Pediatrics

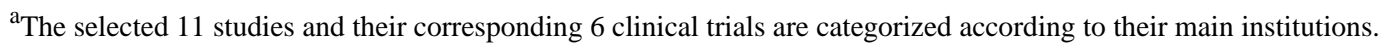

${ }^{\mathrm{b}}$ No associated clinical studies identified through literature search. 


\section{Noninvasive Inputs}

The types of additional inputs integrated or proposed to be integrated into APS that were identified can be categorized as (1) noninvasive inputs captured through wearable devices (most of them) and (2) invasive inputs of substances measured in body fluids. Most (9/11, 82\%) of the selected studies focused on using noninvasive wearable input for MAPS development. Electrocardiogram (ECG), HR, accelerometers, skin resistance, energy expenditure (EE), and galvanic skin response (GSR) were identified as the noninvasive sensory inputs, and clinical studies were carried out for all these additional inputs, except for ECG for which simulations were conducted. However, it should be noted that wearable devices capable of capturing ECG measurements are currently available but might not have been available at the time the respective studies were carried out. Readers are directed to the study by Iqbal et al [53], which summarizes wearable devices in health care.

The additional inputs were introduced to the APS to address the previously explained limitations such as meals, exercise, stress detection, and illnesses and to counter the delays associated with glucose sensing and insulin action. It is important to analyze what additional signals have been used to counter these limitations and how they have been used in the APS design. A large portion of the studies $(7 / 11,64 \%)$ focused on exercise detection. They mainly used HR, accelerometer, and $\mathrm{EE}$ (also referred to as metabolic equivalent [MET]) for exercise detection.

Turksoy et al [36,37] and Hajizadeh et al [38] used the readily available EE data from wearables, whereas Jacobs et al [42] and Resalat et al [43] used a regression model introduced by Zakeri et al [54] to convert HR and accelerometer data to calculate MET. Stenerson et al [50] used HR and accelerometer data, and DeBoer et al [51] used HR data to identify exercise through predefined threshold values. It can be identified that exercise detection was the main focus of previous studies because of its practical importance.

Hypoglycemia prediction, using additional physiological signals, was the next popular approach to MAPS design. Predicting hypoglycemia in advance helps mitigate the glucose-sensing delays. Khan et al [48] and Qaisar et al [49] used HR, ECG (QT interval), and skin resistance for hypoglycemia detection. They identified the QT interval as the most prominent input and skin resistance as the least important input in hypoglycemia prediction. Turksoy et al [55] used EE and GSR to develop a module for hypoglycemia prediction. Stress detection was identified as another important aspect for MAPS design, where Turksoy et al [36,37] focused on using GSR signals. Patek [31], in his review, discusses a variety of other potential examples of how wearable sensory inputs can be used for MAPS design. They include the use of step counts, GPS, electroencephalography, chewing detection, finger and arm motion detection, and sleep detection data.

Managing meal effects is vital in APS development and at present it is challenging because of the heavy user burden, inaccuracies in carbohydrate counting, and forgetting to bolus. Turksoy et al [56,57] developed meal detection and carbohydrate estimation algorithms based on CGM measurements. However, in this survey, our focus was specifically on the use of MAPS design. Additional signals explored in the analyzed studies were not specifically used to improve glucose regulation related to meals.

\section{Invasive Inputs}

People with T1D who choose not to conduct multiple daily blood glucose level tests and use multiple daily injections are currently compelled to use minimally invasive CGM and CSII devices. This requires users to take necessary steps to regularly change the sensors [26,58-61]. Hence, an additional invasive sensor might be identified as practically burdensome. However, there exists the possibility of integrating additional sensors in currently used devices such as CGM and CSII to avoid additional user burden. Previous studies have identified relationships between invasive inputs and T1D (eg, ketone sensors to identify diabetic ketoacidosis [62]). Although rich relationships exist, progress is stunted because of the lack of sensors for carrying out continuous measurements. At present, real-time interstitial insulin sensors and ketone sensors are being developed [63].

Quiroz and Femat [46] and Quiroz et al [47] identified lactate and adrenaline as 2 important invasive inputs that were directly integrated as inputs in the controller. They are used in detecting exercise and hypoglycemia, respectively, which are important aspects in APS design to address the limitations identified previously. The studies described did not focus on clinical trials based on these additional invasive inputs, which again highlights the limited research conducted in the area because of the bottleneck in sensor development.

\section{MAPS Architectures}

The additional inputs identified in the previous section have been integrated into different architectures to augment the controllers (Table 3). They have been (1) used to switch controller modes through activity detection, (2) directly incorporated in the controller for decision-making, and (3) used for the development of intermediate modules for the controller (eg, hypoglycemia and meal detection). 
Table 3. Summary of selected studies. Additional summarization is provided in Multimedia Appendix 3 [38,42,43,46-50].

\begin{tabular}{|c|c|c|c|c|}
\hline Study & Additional inputs & Control algorithm & Architecture & Validation \\
\hline Quiroz et al [46] & Lactate and adrenaline & $H_{\infty}$ controller & Additional inputs directly integrated & MATLAB simulation \\
\hline Quiroz et al [47] & Lactate and adrenaline & $H_{\infty}$ controller & Additional inputs directly integrated & MATLAB simulation \\
\hline Khan et al [48] & $\begin{array}{l}\mathrm{ECG}^{\mathrm{a}}, \mathrm{HR}^{\mathrm{b}} \text {, and skin resis- } \\
\text { tance }\end{array}$ & $\mathrm{PID}^{\mathrm{c}}$ controller & $\begin{array}{l}\text { Fuzzy fusion controller to fuse the additional } \\
\text { input to prompt glucagon infusion (dual hor- } \\
\text { mone) }\end{array}$ & MATLAB simulation \\
\hline Qaisar et al [49] & $\begin{array}{l}\mathrm{ECG}, \mathrm{HR} \text {, and skin resis- } \\
\text { tance }\end{array}$ & $\begin{array}{l}\text { Neural network pre- } \\
\text { dictive controller }\end{array}$ & $\begin{array}{l}\text { Fuzzy fusion controller to fuse the additional } \\
\text { input to prompt glucagon infusion (dual hor- } \\
\text { mone) }\end{array}$ & MATLAB simulation \\
\hline $\begin{array}{l}\text { Stenerson et al } \\
{[50]}\end{array}$ & HR and accelerometer & PLGS $^{\mathrm{d}}$ algorithm & Additional inputs used to switch between modes & Simulator (not specified) \\
\hline DeBoer et al [51] & $\mathrm{HR}$ & Control to range & $\begin{array}{l}\text { Additional inputs used to switch between modes } \\
\text { (only basal rate is controlled) }\end{array}$ & Clinical study \\
\hline Jacobs et al [42] & $\begin{array}{l}\mathrm{EE}^{\mathrm{e}} \text { (HR and accelerometer } \\
\text { used to calculate) }\end{array}$ & FMPD $^{f}$ controller & $\begin{array}{l}\text { Additional inputs used to switch the controller } \\
\text { to a different mode (dual hormone) }\end{array}$ & Simulation; clinical study \\
\hline Resalat et al [43] & $\begin{array}{l}\text { MET }^{\mathrm{g}} \text { (HR and accelerome- } \\
\text { ter) }\end{array}$ & $\begin{array}{l}\text { Adaptive run-to-run } \\
\text { MPC }^{\text {h }}\end{array}$ & $\begin{array}{l}\text { Inputs used to calculate MET, which is directly } \\
\text { used by the controller for decision-making; meal } \\
\text { data also provided to the controller }\end{array}$ & Simulation \\
\hline Turksoy et al [36] & $\mathrm{EE}$ and GSR ${ }^{\mathrm{i}}$ & $\mathrm{GPC}^{\mathrm{j}}$ & $\begin{array}{l}\text { Additional inputs integrated directly; ARMAX }{ }^{\mathrm{k}} \text {, } \\
\text { recursive least squares, and constrained optimiza- } \\
\text { tion used }\end{array}$ & Clinical study \\
\hline Turksoy et al [37] & EE and GSR & GPC & $\begin{array}{l}\text { Additional inputs integrated directly; time- } \\
\text { varying forgetting factor for WRLS }{ }^{1} \text { algorithm } \\
\text { and trajectory tracking }\end{array}$ & Clinical study \\
\hline $\begin{array}{l}\text { Hajizadeh et al } \\
\text { [38] }\end{array}$ & $\mathrm{EE}(\mathrm{MET})$ & Adaptive MPC & $\begin{array}{l}\text { Additional inputs integrated directly into the } \\
\text { controller. Recursive subspace identification } \\
\text { techniques, } \text { PIC }^{\mathrm{m}} \text {, and meal estimates also used } \\
\text { as inputs to the controller }\end{array}$ & Simulation \\
\hline
\end{tabular}

${ }^{\mathrm{a}} \mathrm{ECG}$ : electrocardiogram.

${ }^{\mathrm{b}} \mathrm{HR}$ : heart rate.

${ }^{c}$ PID: proportional integral derivative.

${ }^{\mathrm{d}}$ PLGS: predictive low-glucose suspend.

${ }^{\mathrm{e}} \mathrm{EE}$ : energy expenditure.

${ }^{f}$ FMPD: fading memory proportional derivative.

${ }^{\mathrm{g}}$ MET: metabolic equivalent.

${ }^{\mathrm{h}}$ MPC: model predictive control.

${ }^{\mathrm{i}}$ GSR: galvanic skin response.

${ }^{\mathrm{j}} \mathrm{GPC}$ : generalized predictive control.

${ }^{\mathrm{k}}$ ARMAX: autoregressive moving average with external input.

${ }^{\mathrm{l}}$ WRLS: weighted recursive least squares.

${ }^{\mathrm{m}} \mathrm{PIC}$ : plasma insulin concentration.

Stenerson et al [50], DeBoer et al [51], and Jacobs et al [42] focused on switching the mode of the controller based on detected activity. HR and accelerometer input were used in this approach, where the controller mode was changed through adjusting parameters and thresholds within the controller. Stenerson et al [50] suspended their predictive low-glucose suspend algorithm, and DeBoer et al [51] adjusted the hypoglycemia risk threshold in their control-to-range controller when exercise was detected. Jacobs et al [42] used a fading memory proportional derivative dual hormone controller that, upon the detection of exercise, carried out dosing of insulin and glucagon based on a set of static rules. This approach only focused on activity detection. However, the identified additional inputs may contain valuable information related to the glucose regulation process. Hence, studies have focused on direct integration of the additional inputs for decision-making.

Quiroz and Femat [46], Quiroz et al [47], Resalat et al [43], Turksoy et al [36,37], and Hajizadeh et al [38] focused on direct integration of additional inputs in the controller design. Quiroz and Femat [46] and Quiroz et al [47] directly integrated lactate and adrenaline input into their $H_{\infty}$ control algorithm. Resalat et al [43] developed a run-to-run MPC that used continuous MET data for exercise detection. Turksoy et al [36] integrated EE and 
GSR into a generalized predictive controller by developing time series models using autoregressive moving average with external input, recursive least squares, and constrained optimization techniques. They improved on their work by introducing a time-varying forgetting factor for the weighted recursive least squares algorithm and focusing on trajectory tracking [37]. Hajizadeh et al [38] used recursive subspace identification techniques to develop an adaptive MPC controller incorporating MET input. The continuously integrated inputs such as EE and GSR provided valuable and timely insights regarding the glucose regulatory process, which is valuable.

Designing submodules for the APS has also been widely explored, where the focus has been on using the input to enhance insulin and glucagon infusion and to design safety mechanisms for the APS. These submodules were mainly linked to identified limitations such as meal detection, activity detection, and hypoglycemia detection. Khan et al [48] and Qaisar et al [49] developed a hypoglycemia-detection module using HR, ECG (QT Interval), and skin resistance. In addition to the main controller focusing on insulin infusion, a fuzzy logic fusion controller was introduced to infuse glucagon based on the identified signals during a hypoglycemia event. Turksoy et al [41] performed a clinical trial where hypoglycemia early alarm [55], meal detection [56,64], hypoglycemia prediction, and carbohydrate recommendation [57] modules were integrated into the final APS design. Hajizadeh at al [38] focused on plasma insulin concentration estimation and meal effect estimation modules in their research. Resalat et al [43] proposed and evaluated an insulin sensitivity adaptation algorithm and an adaptive-learning postprandial hypoglycemia prevention algorithm. However, it is important to note that some of these submodules only used existing CGM measurements. Different safety modules have also been introduced, where Turksoy et al [36] and DeBoer et al [51] focused on hypoglycemia and hyperglycemia safety, respectively, through insulin-on-board estimates. The development of submodules enhances the interpretability of the APS operation, which is essential in safety-critical applications. Most of the studies have used submodules in their controllers, both with switching the controller mode through activity detection and when additional inputs are directly integrated. Hence, designing submodules using additional input targeting the identified limitations is beneficial in APS development.

\section{Validation Methodologies}

The designed APS have been validated through simulations and clinical studies (Tables 3 and 4). A variety of physiological models and tools have been used for simulations and different protocols used for clinical trials. The AP is classified as a high-risk medical device by the FDA, which requires proper simulation and testing before conducting clinical trials. However, it is important to note that an FDA-approved simulator is currently unavailable for testing MAPS. In all, 2 groups have focused on developing their own multiple-input simulators [24,25], which would be beneficial for the progress of MAPS development. 
Table 4. Comparison of clinical trial results.

\begin{tabular}{|c|c|c|}
\hline Author & Trial and controller setting & Results \\
\hline Breton et al [52] & $\begin{array}{l}\text { - } 12 \text { adults, randomized crossover trial, 24-hour closed-loop } \\
\text { - } \quad \text { Experiments each with exercise } \\
\text { - } \quad \text { Meal bolus manually calculated }\end{array}$ & $\begin{array}{l}\text { Time in euglycemia }{ }^{\mathrm{b}} \text { for } \mathrm{AP}^{\mathrm{c}} \text { with } \mathrm{HR} \text { and without } \mathrm{HR} \\
\text { overall } 81 \% \text { vs } 75 \% \text {, exercise } 91 \% \text { vs } 85 \% \text {, and overnight } \\
89 \% \text { vs } 84 \% \\
\text { Using HR resulted in fewer hypoglycemic events during } \\
\text { exercise ( } 0 \text { vs } 2)\end{array}$ \\
\hline
\end{tabular}

DeBoer et al [51] • 18 adolescents, randomized crossover trial, 24-hour closedloop experiments each with exercise

- $\quad$ Exercise detection using HR

- Meal bolus manually calculated

Jacobs et al [44]

- $\quad 21$ adults, randomized crossover trial, 22-hour experiments each with exercise

- Exercise-detection algorithm triggered manually

Castle et al [45]

- $\quad 20$ adults, randomized each with exercise

- Exercise-detection algorithm triggered using wearable sensor in $\mathrm{SH}^{\mathrm{e}}$ and $\mathrm{DH}^{\mathrm{f}}$ controllers

Turksoy et al [36,39]

- 3 young adults, seven 32- or 60-hour closed-loop experiments with exercise

- Additional signals integrated continuously

Turksoy et al [37] • $\quad 3$ young adults, 70-hour closed-loop experiments with exercise

- Additional signals integrated continuously

Turksoy et al [40] $\quad$ - 9 young adults, 2-day closed-loop experiments with exercise

- Additional signals integrated continuously

Turksoy et al [41] • $\quad 10$ young adults, eighteen 60-hour closed-loop experiments with exercise

- Additional signals integrated continuously, with submodules
- $\quad$ Time in euglycemia for AP with HR and without HR overall $77 \%$ vs $74 \%$, exercise $96 \%$ vs $87 \%$, and overnight $92 \%$ vs $84 \%$

- Small reduction in hypoglycemic events (0.39 HR-informed AP vs 0.50 without HR)

- Time in euglycemia with exercise detection $67 \%$, without exercise detection $72 \%$, and $\mathrm{SAP}^{\mathrm{d}} 68 \%$

- $\quad$ Time in hypoglycemia ( $<3.9 \mathrm{mmol} / \mathrm{L}) 0.3 \%, 3.1 \%$, and $0.8 \%$, respectively

- $\quad$ Time in hyperglycemia ( $<10 \mathrm{mmol} / \mathrm{L}) 32 \%, 25 \%$, and $31 \%$, respectively

Time in euglycemia overall SH 74.3\%, DH 72\%, PLGS $^{\mathrm{g}}$ $65.2 \%$, and current care $63.1 \%$

- Time in hypoglycemia $2.8 \%, 1.3 \%, 2 \%$, and $3.1 \%$, respectively

- Time in euglycemia $62 \%$ (overnight $75.3 \%$, exercise $55 \%$, and glycemic closed loop 56.1\%)

Time in euglycemia $46.5 \%$

Time in euglycemia $58 \%$

Time in euglycemia $69.9 \%$ for exercise and recovery periods and $76.75 \%$ overall performance

\footnotetext{
${ }^{\mathrm{a}} \mathrm{HR}$ : heart rate. results for the range $70-180 \mathrm{mg} / \mathrm{dL}$ ).

${ }^{\mathrm{c}} \mathrm{AP}$ : artificial pancreas.

${ }^{\mathrm{d}} \mathrm{SAP}$ : sensor-augmented pump.

${ }^{\mathrm{e}} \mathrm{SH}$ : single hormone.

f DH: dual hormone.

g PLGS: predictive low-glucose suspend.

MATLAB was used in most of the studies to conduct simulations. Quiroz et al [46,47] simulated the use of invasive inputs based on the Sorenson model [21], the Bergman minimal model [65], the glucose-adrenaline relationship discussed in the study by Schultes et al [66], and the glucose-lactate relationship discussed in the study by Stuart et al [67]. Khan et al [48] and Qaisar et al [49] also used the Bergman minimal model, as well as simulated meals, ECG, and subcutaneous delays. Jacobs et al [42] used the Hovorka insulin pharmacodynamics model [68], the insulin pharmacokinetics
}

${ }^{\mathrm{b}}$ Euglycemia target range 70-180 mg/dL (Jacobs et al [44] report euglycemia as 3.9-10 mmol/L, range 70.2-180 mg/dL, whereas all other studies report

model by Wilinska et al [69], the glucagon pharmacokinetics model by Lv et al [70], the glucagon pharmacodynamics model by Bakhtiani et al [71], and the exercise model by Hernandez-Ordonez et al [72] for their simulation. Resalat et al [43] and Hajizadeh et al [38] conducted their simulations based on simulators developed by their own research groups $[24,25]$.

DeBoer et al [51], Breton et al [52], and Jacobs et al [44,45] carried out a clinical trial to evaluate their switching mode controller after obtaining FDA and institutional review board 
approvals. Breton et al [52] and DeBoer et al [51] reported a reduction in hypoglycemic events in adolescents and adults, respectively, using $\mathrm{HR}$ in an activity-augmented control architecture. Jacobs et al [44] also achieved a reduction in time spent in hypoglycemia, but there was an increase in the time spent in hyperglycemia when the exercise-augmented control structure was used. Similar results were observed in the subsequent trial by Castle et al [45]. Overall, these randomized crossover trials were able to identify a reduction in hypoglycemia when the activity-augmented control structure was used. It is important to note that activity-augmented APS design might be compromised during different types of exercises (high-intensity training and resistance exercise), which has not been explored. Turksoy et al [39-41] focused on having a medical expert to review each insulin dose before the application and obtained institutional review board approval. They focused on integrating continuous inputs (EE and GSR) into the controller and developing submodules and conducted clinical trials for evaluation. They succeeded in improving the time in target range $(70-180 \mathrm{mg} / \mathrm{dL})$ to $76.75 \%$ with the integration of different submodules into the APS. The identified clinical trials (Table 4) focused on either adolescents, young adults, or adults. The trials comprised both normal closed-loop trials and randomized crossover trials, which evaluated different treatment types and typically ranged in duration from 1 to 4 days. Further longitudinal studies will be beneficial to ascertain the effects of sensor noise and unanticipated dropouts that might arise from the additionally introduced sensors. It is important to conduct trials encompassing all age groups (children, adolescents, and adults) to evaluate the robustness of the controllers because different age groups have different insulin sensitivities, which affects the controller's accuracy.

\section{Discussion}

\section{Principal Findings}

This survey focused on three main verticals: (1) identifying the types of additional input signals used, (2) analyzing different APS control methodologies, and (3) exploring MAPS validation methodologies. In this section, a summary of the findings based on these aspects, a discussion on the feasibility of MAPS, a comparison of clinical trial results, and limitations of the conducted survey are discussed.

Most of the identified inputs were noninvasive, captured through wearable devices. However, the effectiveness of invasive inputs has also been analyzed through simulations. Lactate and adrenaline were the identified invasive inputs used for exercise detection and hypoglycemia detection. EE (or MET) can be identified as the most frequent additional input used in APS development. EE is able to detect exercise, which helps mitigate the related APS limitations identified previously. Hypoglycemia prediction has been carried out through the use of inputs such as ECG, HR, skin resistance, EE, and GSR. GSR has also been used effectively as an indicator of stress. HR-, EE-, GSR-, and accelerometer-based studies have been evaluated through clinical trials mainly because of the easy access through wearable devices. The technological advancements in wearable devices would be beneficial for the development of MAPS. A summary of the distribution of different additional inputs used in the final APS design and their main focus aspects in the selected studies is provided in Figure 3. 
Figure 3. Distribution of additional inputs used in the final artificial pancreas systems design and their main focus aspects. Only the additional inputs used in the final design are presented. Input variables used to synthesize the final inputs have been removed. ECG: electrocardiogram; EE: energy expenditure; HR: heart rate; GSR: galvanic skin response; MET: metabolic equivalent.

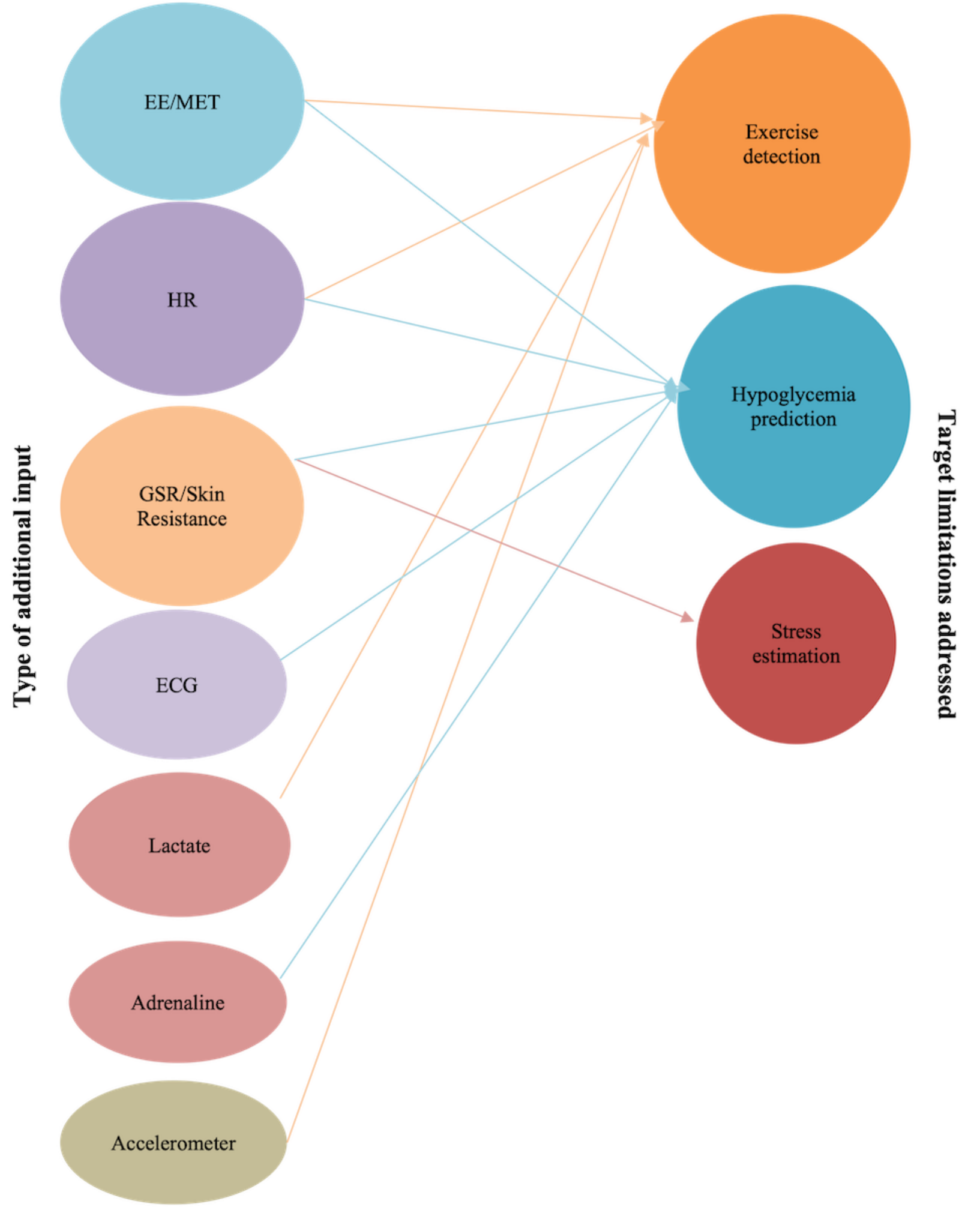

Most of the studies $(8 / 11,73 \%)$ focused on augmenting single-hormone APS compared with dual-hormone systems. Identifying additional inputs that can be used to address current limitations and directly integrating those inputs into the controller has shown promise. The development of submodules based on these limitations and switching the mode of the controller through activity detection can also be identified as effective approaches to MAPS design. Different control algorithms and architecture have been proposed in previous research. Adaptive model-based controlling methods have been frequently used for controller development.

Validations were carried out in the studies in silico $(7 / 11,63 \%)$ as well as in vivo $(4 / 11,36 \%)$. Both quantitative and qualitative metrics were used to evaluate the effectiveness of the proposed 
systems. The time in hypoglycemia, euglycemia, and hyperglycemia ranges as well as the number of hypoglycemic events were some of these measures. However, comparison of the results is subjective because of the different physiological models used in the simulators and different protocols (exercise, meals, and age groups) used in the clinical studies. Furthermore, some of the studies included additional modules such as hypoglycemia alarms and meal detection, which were unrelated to the analyzed additional inputs in this study. This further limited a valuable interstudy statistical analysis to understand the impact of the proposed additional Inputs. However, an analysis of comparable studies within the same research group has been presented in the previous section. It is important to mention that 2 groups had focused on developing their own simulators $[24,25]$ because currently available simulators did not have other multiple inputs incorporated. The rest of the studies had combined different physiological models in previous research to simulate the additional variables. At present, such a validated simulator is yet to be developed for MAPS. The development of an FDA-approved simulator for MAPS would be beneficial to test and compare different proposed control architectures to statistically evaluate their performance and the progress in this area. The studies analyzed in the survey have obtained FDA and institutional review board approvals to conduct clinical trials.

It is important to review the patents published related to APS to identify possible technological advancements. We conducted a search on Google Patents for the period January 2005 to May 2021 and identified 2 patents associated with MAPS (Multimedia Appendix $4[73,74])$. Both the patents were associated with the Illinois Institute of Technology research group identified in the previous section. Patent ID US8690820B2 [73] presented a device where a glucose sensor and physiological status-monitoring system communicate with an automatic controller for glucose control. The controller also included a module to predict future glucose levels. Patent ID US10646650B2 [74] introduced additional modules for recursive model identification of hypoglycemia and hyperglycemia early alert and alarm, plasma insulin concentration estimation, physical activity assessment, stress detection and assessment, sleep detection, and sensor and pump fault detection and diagnosis. The aforementioned proposed modules using physiological signals were identified in the previous section.

\section{Feasibility of MAPS}

Different additional inputs have been identified and used to address limitations identified in current generation APS. However, more signals and relationships need to be explored to address limitations such as meal and illness estimation. It is important to quantify the improvement of the APS through the integration of additional input signals. The benefits should outweigh the burden of using the external sensors.

The results of the proposed approaches can be analyzed based on their clinical trials, which provides a fairer interpretation compared with the simulations. However, it should be noted that comparison between trials is not straightforward because of the different protocols (meals and exercise) and the number of participants involved. The identified clinical trials improved the time in euglycemia range and showed a reduction in hypoglycemic events when additional inputs were used. However, further trials need to be conducted with larger cohorts and trial durations to ensure the effectiveness of the systems.

The noise and instability associated with wearable sensors also need to be evaluated because they could have a detrimental effect on the controllers. Precautionary measures should be set in place to ensure patient safety during such circumstances. It is also important to note that the real-world application of MAPS would be very complex. For example, a person with T1D might not wear additional wearables during sleep, which might require the controller to work in highly dynamic environments. Hence, it is important to evaluate such scenarios through simulations and clinical studies conducted for longer durations.

\section{Conclusions and Comparison With Prior Work}

Kudva et al [30] analyzed the clinical importance of incorporating additional signals, and Cinar [29] and Patek [31] analyzed the current limitations in APS design and the approach to MAPS development. In this survey, we analyzed existing APS designs to identify the types of input variables used, control techniques, architectures, and validation methodologies. This survey was restricted to studies that proposed APS. However, research studies exist that aim to identify relationships between various physiological signals and T1D. The identification of such relationships would be beneficial for the development of MAPS. Previous research has also focused on designing submodules such as meal detection [56], carbohydrate recommendation [57], and hypoglycemia prediction [55] modules for APS. Given the scope of this survey, such submodules were only identified and only the final integrated APS were evaluated. This survey mainly focused on the technical aspects of MAPS development. It is also important to explore and evaluate the corresponding practical aspects (eg, additional user burden, sensor failures, and psychosocial impact).

The integration of additional signals is an approach to mitigate the current limitations of the APS. Most of the integrated additional inputs in previous research are from wearables. The widespread availability of wearables could be seen as a factor facilitating MAPS. Past studies have mainly focused on using the additional inputs for detecting exercise (HR, accelerometer, and EE), hypoglycemia (ECG, HR, EE, and GSR), and stress (GSR). In future, these additional sensors might also be valuable in capturing other physiological changes such as illnesses, alcohol consumption, and seasonal variations. Previous randomized crossover studies were able to obtain lower time in hypoglycemia and improvements in the normal glycemic range when additional inputs were integrated. However, these systems need to be improved to obtain better time in target range for glucose to improve the quality of life of people with T1D. The lack of an FDA-approved simulator for testing the identified additional input can be identified as a major constraint regarding the development of MAPS. It is important to explore different additional inputs further to establish relationships with glucose regulation and use them to address the identified limitations. The practical complexities and psychosocial aspects associated with MAPS need to be evaluated to develop effective APS. 


\section{Acknowledgments}

This research was funded by, and has been delivered in partnership with, the Australian National University (ANU) School of Computing and Our Health in Our Hands, a strategic initiative of the ANU that aims to transform health care by developing new personalized health technologies and solutions in collaboration with patients, clinicians, and health care providers. The authors wish to thank Dr Anne Parkinson, Dr Nicola Brew-Sam, Dr Zakir Hossain, Dr Nicolo Malagutti, members from the Our Health in Our Hands Health Experience Team, including those with type 1 diabetes mellitus, and the ANU library for providing valuable insights in preparing this survey.

\section{Authors' Contributions}

$\mathrm{CH}$ contributed to all aspects of this work and wrote the original manuscript. $\mathrm{CH}$, ED, and HS were responsible for conceptualizing the study and served as the 3 independent reviewers. ED, HS, JD, CJN, and DON critically reviewed, commented on, and revised the manuscript. CJN, HS, and ED contributed to the oversight and leadership responsibilities for the research activity planning, resourcing, and execution.

\section{Conflicts of Interest}

None declared.

\section{Multimedia Appendix 1}

Search query formulation.

[DOCX File, 24 KB-Multimedia Appendix 1]

\section{Multimedia Appendix 2}

Quality assessment.

[DOCX File , 29 KB-Multimedia Appendix 2]

\section{Multimedia Appendix 3}

Summary of additional inputs and simulation models.

[DOCX File, 26 KB-Multimedia Appendix 3]

\section{Multimedia Appendix 4}

Patents associated with multi-input artificial pancreas systems.

[DOCX File, 25 KB-Multimedia Appendix 4]

\section{References}

1. DiMeglio LA, Evans-Molina C, Oram RA. Type 1 diabetes. Lancet 2018 Jun;391(10138):2449-2462. [doi: 10.1016/s0140-6736(18)31320-5]

2. Roep B. Improving clinical islet transplantation outcomes. Nephrol Dial Transplant 2020;21(suppl_4):507-518. [doi: 10.1093/ndt/21.suppl_4.iv507]

3. Vliebergh J, Lefever E, Mathieu C. Advances in newer basal and bolus insulins: impact on type 1 diabetes. Curr Opin Endocrinol Diabetes Obes 2021 Feb 01;28(1):1-7. [doi: 10.1097/MED.0000000000000599] [Medline: 33315628]

4. Shah R, Patel M, Maahs D, Shah V. Insulin delivery methods: past, present and future. Int J Pharma Investig 2016;6(1):1. [doi: 10.4103/2230-973x.176456]

5. Villena Gonzales W, Mobashsher A, Abbosh A. The progress of glucose monitoring-a review of invasive to minimally and non-invasive techniques, devices and sensors. Sensors (Basel) 2019 Mar 15;19(4):800 [FREE Full text] [doi: 10.3390/s19040800] [Medline: 30781431]

6. The Diabetes Control and Complications Trial Research Group. The effect of intensive treatment of diabetes on the development and progression of long-term complications in insulin-dependent diabetes mellitus. Retina 1994;14(3):286-287. [doi: 10.1097/00006982-199414030-00022]

7. Viaene A, Van Daele T, Bleys D, Faust K, Massa GG. Fear of hypoglycemia, parenting stress, and metabolic control for children with type 1 diabetes and their parents. J Clin Psychol Med Settings 2017 Mar;24(1):74-81. [doi: 10.1007/s10880-017-9489-8] [Medline: 28280962]

8. Castensøe-Seidenfaden P, Reventlov Husted G, Teilmann G, Hommel E, Olsen BS, Kensing F. Designing a self-management app for young people with type 1 diabetes: methodological challenges, experiences, and recommendations. JMIR Mhealth Uhealth 2017 Oct 23;5(10):e124 [FREE Full text] [doi: 10.2196/mhealth.8137] [Medline: 29061552] 
9. Clemens AH, Chang PH, Myers RW. The development of Biostator, a glucose controlled insulin infusion system (GCIIS). Horm Metab Res 1977;Suppl 7:23-33. [Medline: $\underline{\text { 873440] }}$

10. Cobelli C, Renard E, Kovatchev B. Artificial pancreas: past, present, future. Diabetes 2011 Nov;60(11):2672-2682 [FREE Full text] [doi: 10.2337/db11-0654] [Medline: 22025773]

11. Summary of safety and effectiveness data (SSED). PMA P160017: FDA Summary of Safety and Effectiveness Data. URL: https://www.accessdata.fda.gov/cdrh docs/pdf16/p160017b.pdf [accessed 2022-02-07]

12. Sherwood JS, Russell SJ, Putman MS. New and emerging technologies in type 1 diabetes. Endocrinol Metab Clin North Am 2020 Dec;49(4):667-678 [FREE Full text] [doi: 10.1016/j.ecl.2020.07.006] [Medline: 33153673]

13. Bequette B. A critical assessment of algorithms and challenges in the development of a closed-loop artificial pancreas. Diabetes Technol Ther 2005 Feb;7(1):28-47. [doi: 10.1089/dia.2005.7.28] [Medline: 15738702]

14. Doyle FJ, Huyett LM, Lee JB, Zisser HC, Dassau E. Closed-loop artificial pancreas systems: engineering the algorithms. Diabetes Care 2014 Apr 22;37(5):1191-1197 [FRE Full text] [doi: 10.2337/dc13-2108] [Medline: 24757226]

15. Pinsker JE, Lee JB, Dassau E, Seborg DE, Bradley PK, Gondhalekar R, et al. Randomized Crossover Comparison of Personalized MPC and PID Control Algorithms for the Artificial Pancreas. Diabetes Care 2016 Jul;39(7):1135-1142 [FREE Full text] [doi: 10.2337/dc15-2344] [Medline: 27289127]

16. Turksoy K, Cinar A. Adaptive control of artificial pancreas systems - a review. J Healthc Eng 2014 Mar;5(1):1-22 [FREE Full text] [doi: 10.1260/2040-2295.5.1.1] [Medline: 24691384]

17. Marmarelis V, Mitsis G, Daskalaki E, Diem P, Mougiakakou S. Adaptive algorithms for personalized diabetes treatment. In: Data-driven Modeling for Diabetes. Switzerland: Springer; 2014.

18. Bothe MK, Dickens L, Reichel K, Tellmann A, Ellger B, Westphal M, et al. The use of reinforcement learning algorithms to meet the challenges of an artificial pancreas. Expert Rev Med Devices 2013 Sep;10(5):661-673. [doi: 10.1586/17434440.2013.827515] [Medline: 23972072]

19. The content of Investigational Device Exemption (IDE) and Premarket Approval (PMA) applications for artificial pancreas device systems. US Food \& Drug Administration. URL: https://www.fda.gov/regulatory-information/ search-fda-guidance-documents/ content-investigational-device-exemption-ide-and-premarket-approval-pma-applications-artificial [accessed 2022-02-07]

20. Bergman RN, Phillips LS, Cobelli C. Physiologic evaluation of factors controlling glucose tolerance in man: measurement of insulin sensitivity and beta-cell glucose sensitivity from the response to intravenous glucose. J Clin Invest 1981 Dec 1;68(6):1456-1467 [FREE Full text] [doi: 10.1172/jci110398] [Medline: 7033284]

21. Sorensen JT. A physiologic model of glucose metabolism in man and its use to design and assess improved insulin therapies for diabetes. Massachusetts Institute of Technology, Dept. of Chemical Engineering. 1985. URL: https://dspace.mit.edu/ handle/1721.1/15234 [accessed 2022-02-07]

22. Wilinska ME, Chassin LJ, Acerini CL, Allen JM, Dunger DB, Hovorka R. Simulation environment to evaluate closed-loop insulin delivery systems in type 1 diabetes. J Diabetes Sci Technol 2010 Jan 01;4(1):132-144 [FREE Full text] [doi: 10.1177/193229681000400117] [Medline: 20167177]

23. Visentin R, Campos-Náñez E, Schiavon M, Lv D, Vettoretti M, Breton M, et al. The UVA/Padova type 1 diabetes simulator goes from single meal to single day. J Diabetes Sci Technol 2018 Mar 16;12(2):273-281 [FREE Full text] [doi: 10.1177/1932296818757747] [Medline: 29451021]

24. Rashid M, Samadi S, Sevil M, Hajizadeh I, Kolodziej P, Hobbs N, et al. Simulation software for assessment of nonlinear and adaptive multivariable control algorithms: glucose - insulin dynamics in type 1 diabetes. Comput Chem Eng 2019 Dec 02;130:106565 [FREE Full text] [doi: 10.1016/j.compchemeng.2019.106565] [Medline: 32863472]

25. Resalat N, El Youssef J, Tyler N, Castle J, Jacobs PG. A statistical virtual patient population for the glucoregulatory system in type 1 diabetes with integrated exercise model. PLoS One 2019 Jul 25;14(7):e0217301 [FREE Full text] [doi: 10.1371/journal.pone.0217301] [Medline: 31344037]

26. Brew-Sam N, Chhabra M, Parkinson A, Hannan K, Brown E, Pedley L, et al. Experiences of young people and their caregivers of using technology to manage type 1 diabetes mellitus: systematic literature review and narrative synthesis. JMIR Diabetes 2021 Feb 2;6(1):e20973 [FREE Full text] [doi: 10.2196/20973] [Medline: 33528374]

27. Pease A, Lo C, Earnest A, Kiriakova V, Liew D, Zoungas S. Time in range for multiple technologies in type 1 diabetes: a systematic review and network meta-analysis. Diabetes Care 2020 Aug;43(8):1967-1975. [doi: 10.2337/dc19-1785] [Medline: $\underline{32669412]}$

28. Peters TM, Haidar A. Dual-hormone artificial pancreas: benefits and limitations compared with single-hormone systems. Diabet Med 2018 May 11;35(4):450-459. [doi: 10.1111/dme.13581] [Medline: 29337384]

29. Cinar A. Multivariable adaptive artificial pancreas system in type 1 diabetes. Curr Diab Rep 2017 Aug 15;17(10):88. [doi: 10.1007/s11892-017-0920-1] [Medline: 28812204]

30. Kudva YC, Carter RE, Cobelli C, Basu R, Basu A. Closed-loop artificial pancreas systems: physiological input to enhance next-generation devices. Diabetes Care 2014 Apr 22;37(5):1184-1190 [FREE Full text] [doi: 10.2337/dc13-2066] [Medline: 24757225]

31. Patek S. Multiple-Signal Artificial Pancreas Systems. Amsterdam: Elsevier; 2019. 
32. Kesavadev J, Srinivasan S, Saboo B, Krishna BM, Krishnan G. The do-it-yourself artificial pancreas: a comprehensive review. Diabetes Ther 2020 Jul 30;11(6):1217-1235 [FREE Full text] [doi: 10.1007/s13300-020-00823-z] [Medline: $\underline{32356245]}$

33. Our health in our hands. Australian National University. URL: https://www.anu.edu.au/research/research-initiatives/ our-health-in-our-hands [accessed 2022-02-07]

34. Liberati A, Altman DG, Tetzlaff J, Mulrow C, Gøtzsche PC, Ioannidis JP, et al. The PRISMA statement for reporting systematic reviews and meta-analyses of studies that evaluate health care interventions: explanation and elaboration. PLoS Med 2009 Jul 21;6(7):e1000100 [FREE Full text] [doi: 10.1371/journal.pmed.1000100] [Medline: 19621070]

35. CASP Checklists - Critical Appraisal Skills Programme. CASP. URL: https://casp-uk.net/casp-tools-checklists/ [accessed 2022-02-07]

36. Turksoy K, Bayrak E, Quinn L, Littlejohn E, Cinar A. Adaptive multivariable closed-loop control of blood glucose concentration in patients with type 1 diabetes. In: Proceedings of the American Control Conference. 2013 Presented at: American Control Conference; Jun 17-19, 2013; Washington, DC, USA. [doi: 10.1109/acc.2013.6580275]

37. Turksoy K, Quinn L, Littlejohn E, Cinar A. Multivariable adaptive identification and control for artificial pancreas systems. IEEE Trans Biomed Eng 2014 Mar;61(3):883-891. [doi: 10.1109/tbme.2013.2291777]

38. Hajizadeh I, Rashid M, Samadi S, Sevil M, Hobbs N, Brandt R, et al. Adaptive personalized multivariable artificial pancreas using plasma insulin estimates. J Process Control 2019 Aug;80:26-40. [doi: 10.1016/j.jprocont.2019.05.003]

39. Turksoy K, Bayrak ES, Quinn L, Littlejohn E, Cinar A. Multivariable adaptive closed-loop control of an artificial pancreas without meal and activity announcement. Diabetes Technol Ther 2013 May;15(5):386-400 [FREE Full text] [doi: 10.1089/dia.2012.0283] [Medline: 23544672]

40. Turksoy K, Quinn LT, Littlejohn E, Cinar A. An integrated multivariable artificial pancreas control system. J Diabetes Sci Technol 2014 May 07;8(3):498-507 [FREE Full text] [doi: 10.1177/1932296814524862] [Medline: 24876613]

41. Turksoy K, Hajizadeh I, Hobbs N, Kilkus J, Littlejohn E, Samadi S, et al. Multivariable artificial pancreas for various exercise types and intensities. Diabetes Technol Ther 2018 Oct;20(10):662-671 [FREE Full text] [doi: 10.1089/dia.2018.0072] [Medline: 30188192]

42. Jacobs PG, Resalat N, El Youssef J, Reddy R, Branigan D, Preiser N, et al. Incorporating an exercise detection, grading, and hormone dosing algorithm into the artificial pancreas using accelerometry and heart rate. J Diabetes Sci Technol 2015 Oct 05;9(6):1175-1184 [FREE Full text] [doi: 10.1177/1932296815609371] [Medline: 26438720]

43. Resalat N, Hilts W, Youssef JE, Tyler N, Castle JR, Jacobs PG. Adaptive control of an artificial pancreas using model identification, adaptive postprandial insulin delivery, and heart rate and accelerometry as control inputs. J Diabetes Sci Technol 2019 Nov 09;13(6):1044-1053 [FREE Full text] [doi: 10.1177/1932296819881467] [Medline: 31595784]

44. Jacobs PG, El Youssef J, Reddy R, Resalat N, Branigan D, Condon J, et al. Randomized trial of a dual-hormone artificial pancreas with dosing adjustment during exercise compared with no adjustment and sensor-augmented pump therapy. Diabetes Obes Metab 2016 Nov 15;18(11):1110-1119 [FREE Full text] [doi: 10.1111/dom.12707] [Medline: 27333970]

45. Castle JR, El Youssef J, Wilson LM, Reddy R, Resalat N, Branigan D, et al. Randomized outpatient trial of single- and dual-hormone closed-loop systems that adapt to exercise using wearable sensors. Diabetes Care 2018 Jul 11;41(7):1471-1477 [FREE Full text] [doi: 10.2337/dc18-0228] [Medline: 29752345]

46. Quiroz G, Femat R. Theoretical blood glucose control in hyper- and hypoglycemic and exercise scenarios by means of an H(infinity) algorithm. J Theor Biol 2010 Mar 07;263(1):154-160. [doi: 10.1016/j.jtbi.2009.11.015] [Medline: 19962391]

47. Quiroz G, Flores-Gutiérrez CP, Femat R. Suboptimal hyperglycemia control on T1DM accounting biosignals of exercise and nocturnal hypoglycemia. Optim Control Appl Method 2011 Jan 31;32(2):239-252. [doi: 10.1002/oca.989]

48. Khan SH, Khan AH, Khan ZH. Artificial pancreas coupled vital signs monitoring for improved patient safety. Arab J Sci Eng 2012 Dec 6;38(11):3093-3102. [doi: 10.1007/s13369-012-0456-2]

49. Qaisar SB, Khan S, Imtiaz S. Neural network and physiological parameters based control of artificial pancreas for improved patient safety. In: Computational Science and Its Applications. Berlin, Heidelberg: Springer; 2012.

50. Stenerson M, Cameron F, Wilson DM, Harris B, Payne S, Bequette BW, et al. The impact of accelerometer and heart rate data on hypoglycemia mitigation in type 1 diabetes. J Diabetes Sci Technol 2014 Jan;8(1):64-69 [FREE Full text] [doi: 10.1177/1932296813516208] [Medline: 24876539]

51. DeBoer MD, Cherñavvsky DR, Topchyan K, Kovatchev BP, Francis GL, Breton MD. Heart rate informed artificial pancreas system enhances glycemic control during exercise in adolescents with T1D. Pediatr Diabetes 2017 Dec 13;18(7):540-546. [doi: 10.1111/pedi.12454] [Medline: 27734563]

52. Breton MD, Brown SA, Karvetski CH, Kollar L, Topchyan KA, Anderson SM, et al. Adding heart rate signal to a control-to-range artificial pancreas system improves the protection against hypoglycemia during exercise in type 1 diabetes. Diabetes Technol Ther 2014 Aug;16(8):506-511 [FREE Full text] [doi: 10.1089/dia.2013.0333] [Medline: 24702135]

53. Iqbal MH, Aydin A, Brunckhorst O, Dasgupta P, Ahmed K. A review of wearable technology in medicine. J R Soc Med 2016 Oct 11;109(10):372-380 [FREE Full text] [doi: 10.1177/0141076816663560] [Medline: 27729595]

54. Zakeri I, Adolph AL, Puyau MR, Vohra FA, Butte NF. Application of cross-sectional time series modeling for the prediction of energy expenditure from heart rate and accelerometry. J Appl Physiol (1985) 2008 Jul;104(6):1665-1673 [FREE Full text] [doi: 10.1152/japplphysiol.01163.2007] [Medline: 18403453] 
55. Turksoy K, Bayrak ES, Quinn L, Littlejohn E, Rollins D, Cinar A. Hypoglycemia early alarm systems based on multivariable models. Ind Eng Chem Res 2013 Oct 04;52(35):12329-12336 [FREE Full text] [doi: 10.1021/ie3034015] [Medline: 24187436]

56. Turksoy K, Samadi S, Feng J, Littlejohn E, Quinn L, Cinar A. Meal detection in patients with type 1 diabetes: a new module for the multivariable adaptive artificial pancreas control system. IEEE J Biomed Health Inform 2016 Jan;20(1):47-54 [FREE Full text] [doi: 10.1109/JBHI.2015.2446413] [Medline: 26087510]

57. Turksoy K, Kilkus J, Hajizadeh I, Samadi S, Feng J, Sevil M, et al. Hypoglycemia detection and carbohydrate suggestion in an artificial pancreas. J Diabetes Sci Technol 2016 Nov 28;10(6):1236-1244 [FREE Full text] [doi: 10.1177/1932296816658666] [Medline: 27464755]

58. Iturralde E, Tanenbaum ML, Hanes SJ, Suttiratana SC, Ambrosino JM, Ly TT, et al. Expectations and attitudes of individuals with type 1 diabetes after using a hybrid closed loop system. Diabetes Educ 2017 Apr 24;43(2):223-232 [FREE Full text] [doi: 10.1177/0145721717697244] [Medline: 28340542]

59. Lawton J, Blackburn M, Allen J, Campbell F, Elleri D, Leelarathna L, et al. Patients' and caregivers' experiences of using continuous glucose monitoring to support diabetes self-management: qualitative study. BMC Endocrine Disorders 2018 Mar 20;18(1):12 [FREE Full text] [doi: 10.1186/s12902-018-0239-1] [Medline: 29458348]

60. Barnard KD, Wysocki T, Ully V, Mader JK, Pieber TR, Thabit H, et al. Closing the loop in adults, children and adolescents with suboptimally controlled type 1 diabetes under free living conditions: a psychosocial substudy. J Diabetes Sci Technol 2017 Dec 03;11(6):1080-1088 [FREE Full text] [doi: 10.1177/1932296817702656] [Medline: 28367636]

61. Rankin D, Harden J, Barnard K, Bath L, Noyes K, Stephen J, et al. Barriers and facilitators to taking on diabetes self-management tasks in pre-adolescent children with type 1 diabetes: a qualitative study. BMC Endocrine Disorders 2018 Oct 13;18(1):71 [FREE Full text] [doi: 10.1186/s12902-018-0302-y] [Medline: 30316299]

62. Lee MH, Paldus B, Krishnamurthy B, McAuley SA, Shah R, Jenkins AJ, et al. The clinical case for the integration of a ketone sensor as part of a closed loop insulin pump system. J Diabetes Sci Technol 2019 Sep 10;13(5):967-973 [FREE Full text] [doi: 10.1177/1932296818822986] [Medline: $\underline{\text { 30628470] }}$

63. Teymourian H, Moonla C, Tehrani F, Vargas E, Aghavali R, Barfidokht A, et al. Microneedle-based detection of ketone bodies along with glucose and lactate: toward real-time continuous interstitial fluid monitoring of diabetic ketosis and ketoacidosis. Anal Chem 2020 Jan 21;92(2):2291-2300. [doi: 10.1021/acs.analchem.9b05109] [Medline: 31874029]

64. Ramkissoon C, Herrero P, Bondia J, Vehi J. Unannounced meals in the artificial pancreas: detection using continuous glucose monitoring. Sensors (Basel) 2018 Mar 16;18(3):884 [FREE Full text] [doi: 10.3390/s18030884] [Medline: 29547553]

65. Bergman RN, Ider YZ, Bowden CR, Cobelli C. Quantitative estimation of insulin sensitivity. Am J Physiol Endocrinol Metabolism 1979 Jun 01;236(6):E667. [doi: 10.1152/ajpendo.1979.236.6.e667]

66. Schultes B, Jauch-Chara K, Gais S, Hallschmid M, Reiprich E, Kern W, et al. Defective awakening response to nocturnal hypoglycemia in patients with type 1 diabetes mellitus. PLoS Med 2007 Mar 27;4(2):e69 [FREE Full text] [doi:

10.1371/journal.pmed.0040069] [Medline: 17326710]

67. Kreisman SH, Ah Mew N, Halter JB, Vranic M, Marliss EB. Norepinephrine infusion during moderate-intensity exercise increases glucose production and uptake. J Clin Endocrinol Metab 2001 May;86(5):2118-2124. [doi: 10.1210/jcem.86.5.7476] [Medline: 11344216$]$

68. Hovorka R, Canonico V, Chassin LJ, Haueter U, Massi-Benedetti M, Orsini Federici M, et al. Nonlinear model predictive control of glucose concentration in subjects with type 1 diabetes. Physiol Meas 2004 Aug 23;25(4):905-920. [doi: 10.1088/0967-3334/25/4/010] [Medline: 15382830]

69. Wilinska M, Chassin L, Schaller H, Schaupp L, Pieber T, Hovorka R. Insulin kinetics in type-1 diabetes: continuous and bolus delivery of rapid acting insulin. IEEE Trans Biomed Eng 2005 Jan;52(1):3-12. [doi: 10.1109/tbme.2004.839639]

70. Lv D, Breton MD, Farhy LS. Pharmacokinetics modeling of exogenous glucagon in type 1 diabetes mellitus patients. Diabetes Technol Ther 2013 Dec;15(11):935-941 [FREE Full text] [doi: 10.1089/dia.2013.0150] [Medline: 23978267]

71. Bakhtiani P, El Youssef J, Duell A, Branigan D, Jacobs P, Lasarev M, et al. Factors affecting the success of glucagon delivered during an automated closed-loop system in type 1 diabetes. J Diabetes Complications 2015 Jan;29(1):93-98 [FREE Full text] [doi: 10.1016/j.jdiacomp.2014.09.001] [Medline: 25264232]

72. Hernández-Ordoñez M, Campos-Delgado D. An extension to the compartmental model of type 1 diabetic patients to reproduce exercise periods with glycogen depletion and replenishment. J Biomech 2008 Jan;41(4):744-752. [doi: 10.1016/j.jbiomech.2007.11.028] [Medline: $\underline{18206156]}$

73. Automatic insulin pumps using recursive multivariable models and adaptive control algorithms. Google Patent. URL: https:/ /patents.google.com/patent/US8690820B2/en [accessed 2022-02-07]

74. Multivariable artificial pancreas method and system. Google Patent. URL: https://patents.google.com/patent/US10646650B2/ en [accessed 2022-02-07]

\section{Abbreviations \\ ANU: Australian National University \\ AP: artificial pancreas}


APS: artificial pancreas systems

CGM: continuous glucose monitoring

CSII: continuous subcutaneous infusion of insulin

ECG: electrocardiogram

EE: energy expenditure

FDA: Food and Drug Administration

GSR: galvanic skin response

HR: heart rate

MAPS: multi-input artificial pancreas systems

MET: metabolic equivalent

MPC: model predictive control

PRISMA: Preferred Reporting Items for Systematic Reviews and Meta-Analyses

T1D: type 1 diabetes

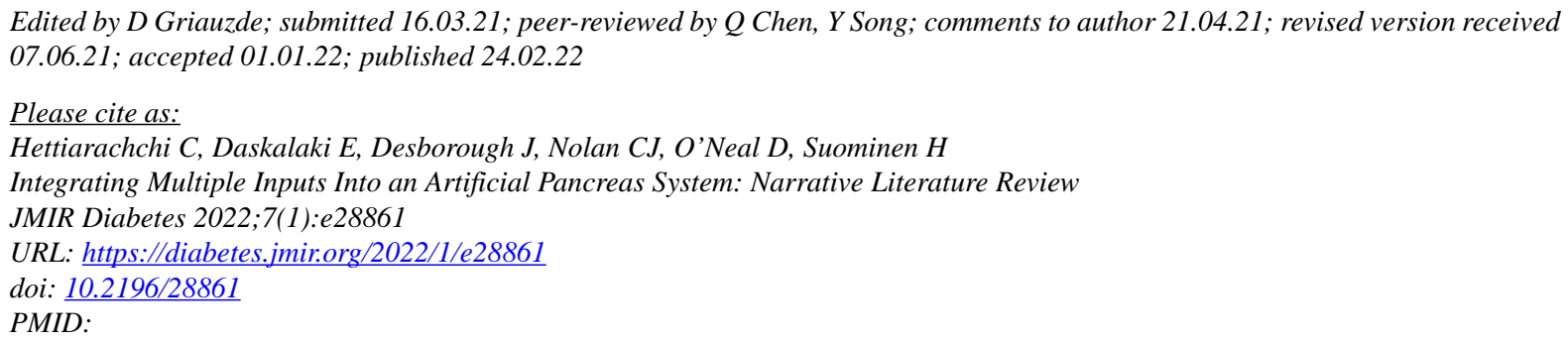

(C) Chirath Hettiarachchi, Elena Daskalaki, Jane Desborough, Christopher J Nolan, David O’Neal, Hanna Suominen. Originally published in JMIR Diabetes (https://diabetes.jmir.org), 24.02.2022. This is an open-access article distributed under the terms of the Creative Commons Attribution License (https://creativecommons.org/licenses/by/4.0/), which permits unrestricted use, distribution, and reproduction in any medium, provided the original work, first published in JMIR Diabetes, is properly cited. The complete bibliographic information, a link to the original publication on https://diabetes.jmir.org/, as well as this copyright and license information must be included. 